\title{
Adsorption of Chromium from Aqueous Solution by Lignocellulosic Biomass (Pinus palustris): Studies on Equilibrium Isotherm, and Kinetics
}

\author{
Narendrakumar $\mathbf{G}^{1 *}$, Senthil kumar $\mathbf{P}^{2}$ \\ ${ }^{1}$ Department of Biotechnology, School of Bio and Chemical Engineering, Sathyabama Institute of Science and Technology, Chennai, Tamilnadu, \\ ${ }^{2}$ Department of Chemical Engineering, School of Bio and Chemical Engineering, Sathyabama Institute of Science and Technology, Chennai, Tamilnadu, \\ India
}

Received: 16/05/2020

Accepted: 13/10/2020

Published: 20/03/2020

\begin{abstract}
Different methods to convert biomass into useful materials and products without generating pollutants will be useful for global environmental protection. The present study deals with the preparation of adsorbent from a suitable lignocellulosic biomass, Pinus palustris seeds. The adsorbent thus prepared will be used for the removal of heavy metals from aqueous solutions. Factors influencing the adsorption characteristics under batch conditions were studied for chromium concentrations in range of $30-150 \mathrm{ppm}$. The studies were conducted to optimize the size of the adsorbent, temperature and contact time. The maximum adsorption is attained at a pH of 6.5 and a dosage of $3 \mathrm{~g}$. The effective temperature for the reaction was at $37^{\circ} \mathrm{C}$. The removal percentage increase when the optimized condition of different parameters such as size, temperature, contact time, concentration, $\mathrm{pH}$ and dosage. The adsorption isotherms showed that the Freundlich Isotherm is a better adsorption model and the characteristic parameters were determined. The results of the kinetic models showed that the pseudo second order kinetics was found to correlate with the experimental data. The present analysis, the absorbent that is produced from Pinus palustris seed has an efficient adsorption for chromium.
\end{abstract}

Keywords: Lignocellulose, adsorption, isotherms, kinetics

\section{Introduction}

Lignocellulosic biomass sources range from forestry to agricultural residues. Banana plant, cotton stalk, bamboo and cotton gin waste are agricultural residues that are not currently used as industrial raw materials on a larger scale $(1,2)$. They contain cellulose, and hemicellulose, which could be used as a source of monomeric sugars for fermentation to produce highvalue products. Long ago, these materials were used as firewood, building materials and animal feed. Nowadays, lignocellulosic materials have expanded its application from pulp and paper products to second-generation biofuel (3). The development of industrial methods to convert biomass into useful materials and products without generating pollutants such as waste gas, wastewater and solid waste material will be useful for global environmental protection (4-5). The adsorbent which we have made is economically feasible and also locally available and has an ability to absorb chromium in higher concentration (6). Once the absorption is completed, it is easy to dispose of the adsorbent by composting, compaction, incineration, ashing, pyrolysis, direct disposal, liquid extraction $(7,8)$. The adsorbent was obtained from pine plant seeds that were powdered and activated. Currently, the removal of heavy metal contaminants from aqueous wastewater is one of the most important environmental issues (9). Even though this issue has been studied for several years, effective and precise treatment methods are still scanty due to its low adsorption capacity, high chemical oxygen demand (COD) and biological chemical demand (BOD) as well as total organic carbon (TOC) due to release of soluble organic compounds contained in the plant materials (10). Excessive toxic heavy metals are often discharged by several industries, like battery manufacturing and tanneries and they are not biodegradable and can lead to accumulation in living organisms, causing various diseases such as cancer, dermatological issues and disorders like itai-itai disease. Monitoring and subsequent removal of toxic heavy metals from industrial wastewater have been made mandatory before their discharge into the environment (11). Chromium, one of the heavy metals, is a widely used industrial metal for electroplating, tannery, leather industry and wood processing industries and the permissible amount chromium is $0.1 \mathrm{mg} / \mathrm{l}(12)$.

Conventional methods applied to remove toxic heavy metals from effluents include chemical precipitation (13), ion exchange (14), carbon adsorption (15) and membrane separation process (16). Among all kinds of adsorption materials, activated carbon

Corresponding author: Narendrakumar G, Department of Biotechnology, School of Bio and Chemical Engineering, Sathyabama Institute of Science and Technology, Chennai, Tamilnadu, Indiagnaren22@ gmail.com 
adsorption has been regarded as an efficient and major technology, but the process is expensive (17). Some main limitations are existent in these alternatives, such as expensive cost, labor - intensive operation, and low efficiency. Therefore, more approaches have been investigated for the development of low-cost adsorbates with a good sorption capacity to remove heavy metal ions from wastewater (18). In recent years, considerable attention has been devoted to the study of application of lignocellulosic biomass as adsorbents (19). Natural materials have an advantage of availability in large quantities, low cost, and good sorption capacity. These are unutilized materials, but they have high potential to be used as adsorbents for heavy metals removal. Adsorption is a versatile treatment technique practiced widely in fine chemical and process industries for wastewater and waste gas treatment (20). The usefulness of the adsorption process lies in the operational simplicity and reuse potential of adsorbents during long term applications (21).

At present, adsorption is widely accepted in environmental treatment applications throughout the world compared with the other methods. The aim of this paper is to use adsorbent obtained by processing of Pinus palustris seeds, and to evaluate its effective removal of chromium from industrial effluents.

\section{Materials Required}

\subsection{Chemicals and materials}

Potassium dichromate $\left(\mathrm{K}_{2} \mathrm{Cr}_{2} \mathrm{O}_{7}\right)$, Potassium iodide $(\mathrm{KI})(1$ M), Sodium thio-sulphate $\left(\mathrm{Na}_{2} \mathrm{~S}_{2} \mathrm{O}_{3}\right) \quad(1 \mathrm{M}), 1 \mathrm{~N}$ and $0.1 \mathrm{~N}$ Hydrochloric acid $(\mathrm{HCl})$, starch solution, Sodium hydroxide $\mathrm{NaOH}(1 \mathrm{M})$, Pinus palustris seeds

\subsection{Methodology}

The sample Pinus palustris seeds (Figure 1) was collected from Chennai and thoroughly washed using tap water. It was then dried in the sun. The further drying of the seeds was done in the dryer at a temperature of $70^{\circ} \mathrm{C}$. When the seeds are completely dried, it was crushed in the blender. This was done until the seeds are crushed into fine particles. The crushed seeds are then sieved into three sizes namely mesh numbers 25 and 52, and pan (22, 23).

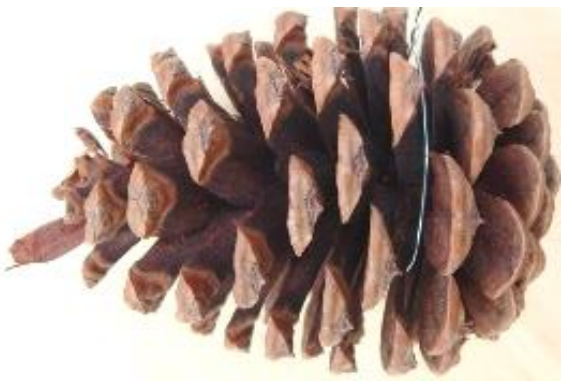

Figure 1: Seeds of Pinus palustris

\subsection{Estimation of chromium}

A stock solution of chromium (IV) solution $\left(1000 \mu \mathrm{g} \mathrm{ml}^{-1}\right)$ was prepared by dissolving $0.2829 \mathrm{~g}$ of $\mathrm{K}_{2} \mathrm{Cr}_{2} \mathrm{O}_{7}$ in $100 \mathrm{ml}$ of deionised double distilled water . The stock solution was further diluted as needed. A stock solution of chromium (III) $(1000 \mu \mathrm{g}$ $\mathrm{ml}^{-1}$ ) was prepared by dissolving $0.2829 \mathrm{~g}$ of $\mathrm{K}_{2} \mathrm{Cr}_{2} \mathrm{O}_{7}$ in $50 \mathrm{ml}$ of deionised double distilled water, adding $1 \mathrm{ml}$ of saturated sodium sulphite solution followed by acidifying with $1 \mathrm{ml}$ of 2.5 $\mathrm{M}$ sulphuric acid, and then boiling for 2 min to remove excess $\mathrm{SO}_{2}$ and diluting with water to $100 \mathrm{ml}$. A suitable volume of this solution was diluted to obtain the working standard. To find the concentration of chromium, the solutions was spectrophotometrically analysis and from the absorbance value concentrations of the solutions were calculated (24).

\subsection{Optimization of Chromium concentration with adsorbent, absorbent size and contact time}

A sample of volume $10 \mathrm{ml}$ of 30,60, 90, 120 and $150 \mathrm{ppm}$ of the chromium solutions were taken and $0.5 \mathrm{~g}$ of the powder ranging from $.075-0.150 \mathrm{~mm}$ was mixed with the solutions. The solutions were kept for $10 \mathrm{~min}$ and then the solutions were filtered. The filtrate was given for spectrophotometry analysis. $30 \mathrm{ml}$ of the solution with the optimized concentration was taken in different beakers and to it $1.5 \mathrm{~g}$ of the adsorbent of sizes pan and mesh no 25 and 52 are added, respectively. These solutions were mixed thoroughly for 30 minutes and filtered and then given for spectrophotometry analysis. $30 \mathrm{ml}$ of the solution containing the optimized concentration and $1.5 \mathrm{~g}$ of the optimized sizes were taken in different beakers. They were kept for time durations of 30, 60, 90 and 120 minutes. The solutions were filtered and spectrophotometry analysis was performed (25)

\subsection{Optimization of temperature}

To optimize the temperature $1.5 \mathrm{~g}$ of the optimum sized adsorbent was taken and heated in an incubator for 2 hours at different temperatures, $32^{\circ} \mathrm{C}, 37^{\circ} \mathrm{C}$ and $45^{\circ} \mathrm{C}$. The adsorbent was added to $30 \mathrm{ml}$ of the solution of optimum concentration and kept for an optimum time (26).

\subsection{Optimization of $\mathrm{pH}$}

To optimize the $\mathrm{pH}, 30 \mathrm{ml}$ of the solution with optimum concentration is maintained with different $\mathrm{pH}$, namely $2,4,6,8$ and 10. To maintain the acidic $\mathrm{pH}$ of 2,4 and $60.01 \mathrm{~N} \mathrm{HCl}$ was added and to maintain the alkaline $\mathrm{pH}$ of 8 and $101 \mathrm{M} \mathrm{NaOH}$ was used. $1.5 \mathrm{~g}$ of the optimized size adsorbent was taken and heated at the optimized temperature and added to the solutions and kept for the optimum contact time (27).

\subsection{Optimization of dosage}

To optimize the dosage, $1.5,3.0$ and $4.5 \mathrm{~g}$ to $30 \mathrm{ml}$ of the solution with optimized concentration was maintained at optimum $\mathrm{pH}$. The adsorbent with optimum size was heated at optimum temperature and added to the solution. These solutions were mixed thoroughly and kept for an optimum contact time (28).

\subsection{Models for adsorption isotherms \\ - Langmuir isotherm (Model 1)}

The theory for Langmuir isotherms assumes monolayer coverage of adsorbate over a homogenous adsorbent surface. Therefore at equilibrium, a saturation point is reached where no further adsorption can occur adsorption takes place at specific homogeneous sites within the adsorbent by the following equation (21).

$\frac{\mathrm{C}_{0}}{\mathrm{~m}}=\frac{\mathrm{abC}_{\mathrm{e}}}{1+\mathrm{aC}_{\mathrm{e}}}$ 
Alternate equation

$\frac{\mathrm{m}}{\mathrm{C}_{0}}=\frac{1}{\mathrm{ab}} \times \frac{1}{\mathrm{C}}+\frac{1}{\mathrm{~b}}$

where $\mathrm{C}_{\mathrm{o}} / \mathrm{m}$ is adsorbed per unit mass of the adsorbent and the concentration of color remaining in the in the solution after adsorption is complete $(\mathrm{Ce})$ by a relation. where $\mathrm{a}$ and $\mathrm{b}$ are constants representing bond energy and adsorption capacity, respectively.

\section{- $\quad$ Freundlich isotherm (Model 2)}

The theory for Freundlich isotherms describes a monolayer and multilayer coverage of adsorption over a heterogeneous surface area adsorbent (22). An adsorption isotherm is an empirical relation between the concentrations of solute on to the surface of an adsorbent to the concentration of the solute in the liquid with which it is contact. In following equation

$\frac{\mathrm{x}}{\mathrm{m}}=\mathrm{KC}^{1 / \mathrm{n}}$

Alternate equation

$\log \frac{x}{m}=\log k+\frac{1}{n} \log C$

where $\mathrm{X} / \mathrm{M}$ is loading, is the amount of impurity adsorbed $(\mathrm{X})$ per unit weight of carbon (M); $\mathrm{C}$ is equilibrium concentration after adsorption; and $\mathrm{k}, \mathrm{n}$ are constants.

\section{- BET (Brunauer- Emmett -Teller) isotherm (Model 3)}

This isotherm describes the physical adsorption of adsorbent on a solid surface and serves as the basis for an important analysis technique for the measurement of the specific surface area of a material (29). In following equation.

$\mathrm{q}_{\mathrm{e}}=\frac{q_{\mathrm{m}} \times \mathrm{K}_{\mathrm{B}} \times \mathrm{C}_{\mathrm{e}} \times \mathrm{Q}_{\mathrm{o}}}{\left(\mathrm{C}_{\mathrm{s}}-\mathrm{C}_{\mathrm{e}}\right)\left\{1+\left(\mathrm{K}_{\mathrm{B}}-1\right)\left(\mathrm{C}_{\mathrm{e}} / \mathrm{C}_{\mathrm{s}}\right)\right\}}$

Alternate equation

$\frac{C_{e}}{\left(C_{s}-C_{e}\right) q_{e}}=\frac{K_{B}-1}{K_{B} \times Q_{0}} \times \frac{C_{e}}{C_{s}}+\frac{1}{K_{B} \times Q_{0}}$

where qe is the amount adsorbed at equilibrium (mg/g) which can be found by qe $=\{(\mathrm{Cs}-\mathrm{Ce}) \mathrm{V}\} / \mathrm{W}$ where $\mathrm{Cs}$ and $\mathrm{Ce}$ are initial and final concentration, respectively; qm is maximum adsorption; and $\mathrm{KB}$ is BET coefficient or equilibrium distribution coefficient and presenting adsorption intensity.

\section{- Tempkin Isotherm (Model 4)}

This isotherm describes the effects of some indirect 1 adsorbate/adsorbate interactions on adsorption isotherms suggested that the heat of adsorption of all the molecules in the layer would decrease linearly with coverage due to these interactions. In the following equation:

$\mathrm{q}_{\mathrm{e}}=\frac{\mathrm{RT}}{\mathrm{b}_{\mathrm{T}}} \times \ln \left(\mathrm{K}_{\mathrm{T}} \mathrm{C}_{\mathrm{e}}\right)$

Alternate equation
$\mathrm{q}_{\mathrm{e}}=\mathrm{B}_{\mathrm{T}} \ln \mathrm{K}_{\mathrm{T}}+\mathrm{B}_{\mathrm{T}} \ln \mathrm{C}_{\mathrm{e}}$

where $\mathrm{KT}(\mathrm{L} / \mathrm{g})$ is the Temkin isotherm constant, bT $(\mathrm{J} / \mathrm{mol})$ is a constant related to heat of sorption, $\mathrm{R}$ is the ideal gas constant $(8.314 \mathrm{~J} / \mathrm{mol} \mathrm{K})$, and $\mathrm{T}$ is absolute temperature $(\mathrm{K})$.

\subsection{Models of sorption kinetics}

- Pseudo First Order Kinetics

The pseudo first order equation (Lagergren's Equation) describes adsorption in solid liquid system based on the sorption capacity of solid. In the following equation

$\frac{d q_{t}}{d t}=K_{1}\left(q_{e}-q_{t}\right)$

Alternate equation

$\log \left(\mathrm{q}_{\mathrm{e}}-\mathrm{q}_{\mathrm{t}}\right)=\log \mathrm{q}_{\mathrm{e}}-\frac{\mathrm{K}_{1}}{2.303} \mathrm{t}$

where qe and qt refer to the adsorption capacities at equilibrium and time $\mathrm{t}$, respectively, in $\mathrm{mg} / \mathrm{g}$ and $\mathrm{k} 1$ is the pseudo-first-order rate constant. Plotting the $\log (\mathrm{qe}-\mathrm{qt}$ ) against $\mathrm{t}$ provides the slope and the intercept as $-\mathrm{k} 1 / 2.303$ and $\log$ (qe), respectively.

- $\quad$ Pseudo Second Order Kinetics

The pseudo second order rate expression has been applied for analyzing chemisorptions kinetics from liquid solutions. In the following equation:

$\frac{d q_{t}}{d t}=K_{1}\left(q_{e}-q_{t}\right)^{2}$

Alternate equation

$\frac{\mathrm{t}}{\mathrm{q}_{\mathrm{t}}}=\frac{1}{\mathrm{~K}_{2}}+\frac{1}{\mathrm{q}_{\mathrm{e}}} \mathrm{t}$

where $\mathrm{k}_{2}$ is the pseudo-second-order rate constant. Plotting the $\mathrm{t} / \mathrm{qt}$ against $\mathrm{t}$ provides the slope and the intercept as (1/qe) and $1 / \mathrm{k}_{2} \mathrm{qe}$, respectively

\section{Results and Discussion}

\subsection{Influence of concentration}

The experiment was carried out with $0.5 \mathrm{~g}$ of the adsorbent which is added to $10 \mathrm{ml}$ of different concentrations $(30,60,90$, 120 and $150 \mathrm{ppm}$ ) and the filtered solutions were given for spectrophotometry analysis. The result showed that percentage adsorption increases with lower concentration. Therefore, the optimum concentration is 30ppm (Figure -2a). The adsorption of chromium on bioabsorbent, was given by Khazaei et al., 2011, (27) they also shows a similar kind of adsorption pattern on the basis of initial concentration and $0.5 \mathrm{ppm}$ shows the maximum adsorption.

\subsection{Influence of size}

Three different sizes of adsorbent have been taken, i.e. pan and mesh nos. 52 and $25.0 .5 \mathrm{~g}$ of the adsorbent of different sizes was kept in $10 \mathrm{ml}$ of the optimized concentration (30ppm) for 10 min. The filtered solutions were given for spectrophotometry analysis. The adsorption concentration of chromium increases as the size of the adsorbent decreases. This is because as the size 
becomes smaller the surface area increases. Therefore, it was concluded that pan size of adsorbent is the optimum size since it shows the highest adsorption percentage (Figure-2b). The adsorption of chromium on almond and apricot shells occurs at the smallest size $(100$ to $150 \mu \mathrm{m})$, given by the Khazaei et al., 2011 (27) which is similar to this experiment.

\subsection{Influence of contact time}

The experiment was carried out with the different time periods, i.e. $30,60,90$ and 120 minutes. $0.5 \mathrm{~g}$ of the pan size adsorbent is added to $10 \mathrm{ml}$ of optimum concentration; $30 \mathrm{ppm}$ of chromium solution. These solutions are kept at different time intervals and filtered and stirred in magnetic stirrer. Then the obtained filtrate was then analyzed by spectrophotometric method and the adsorption percentage was calculated. It was found that as the time increases adsorption percentage increases but after a certain time there is no change in the adsorption percentage. Because after a certain time the adsorption capacity of adsorbent

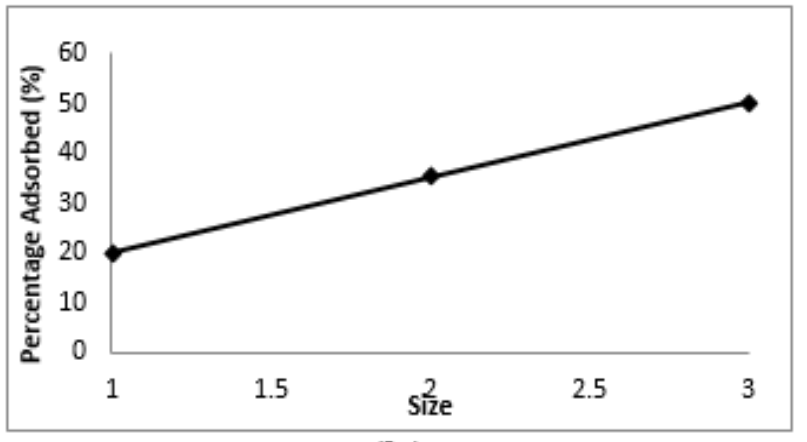

(a)

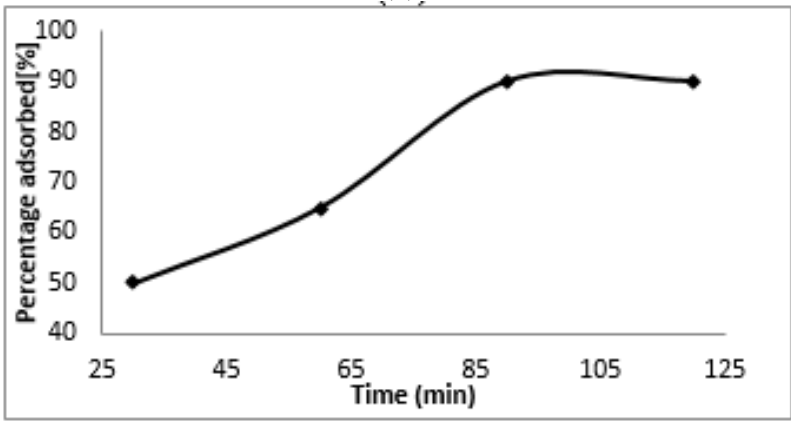

(c)

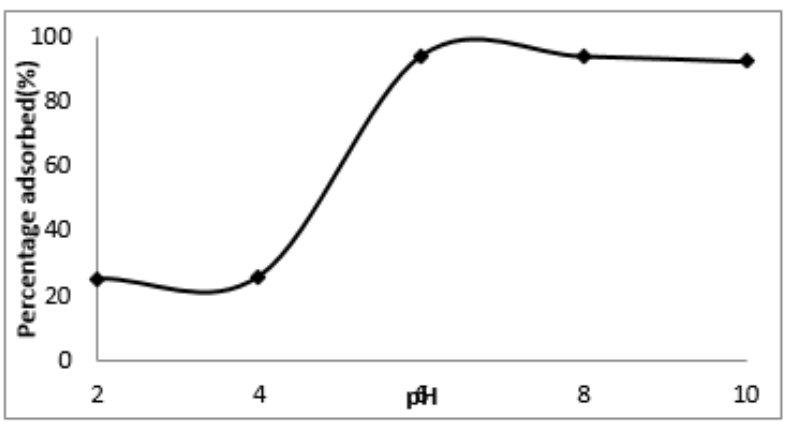

e)

Fig. 2: (a) Influence of size on $\mathrm{Cr}(\mathrm{VI})$ removal; (b) Influence of temperature on $\mathrm{Cr}$ (VI) removal; (c) Influence of contact time on $\mathrm{Cr}(\mathrm{VI})$ removal; (d) Influence of concentration on the adsorption; (e) Influence of $\mathrm{pH}$ on $\mathrm{Cr}(\mathrm{VI})$ removal; and (f) Influence of dosage on $\mathrm{Cr}$ (VI) removal is not increasing and its remain same. Therefore, after $90 \mathrm{~min}$ the absorption ceases. Therefore, the 90 minutes is the optimum contact time at determined optimum loading of the adsorbent (Figure -2c). A comparative study, done by the Hamdi et al.,2001 (31), of $\mathrm{Cu}^{2+}, \mathrm{Pb}^{2+}, \mathrm{Cd}^{2+}$ and $\mathrm{Ni}^{2+}$ adsorption onto chitin and chitosan biopolymers was performed. To attain equilibrium $\mathrm{Cu}^{2+}$ has taken 480 min, $\mathrm{Pb}^{2+}$ has taken $360 \mathrm{~min}, \mathrm{Cd}^{2+}$ has taken 240 min and $\mathrm{Ni}^{2+}$ has taken 480 min., but the chromium adsorption on Pinus palsturis seeds has only taken $90 \mathrm{~min}$, which is very much lesser. The almond shells took $40 \mathrm{~min}$ to reach equilibrium and the apricot shells takes 30 min to reach equilibrium, which was optimized by Khazaei et al., 2011 (27), but it has only lower removal of $\mathrm{Cr}(60 \%)$. The $\mathrm{Cr}^{6+}$ adsorption on Pinus palsturis seeds takes 90 min which is more than the almond and apricot shells, but Pinus palsturis seeds have a removal capacity of $90 \%$ which is more than the former.

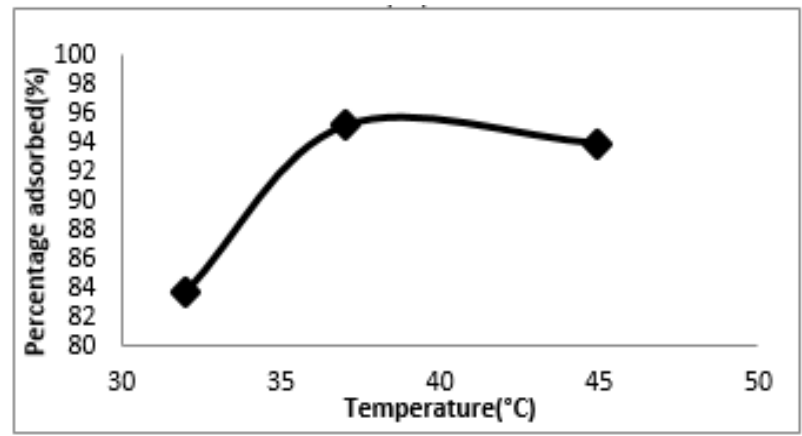

(b)

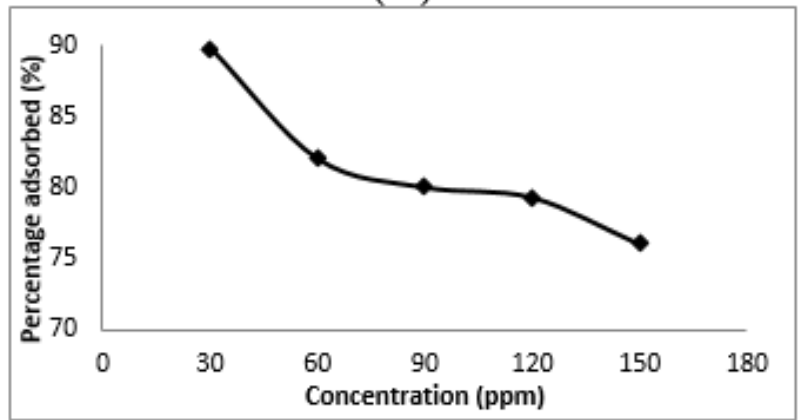

(d)

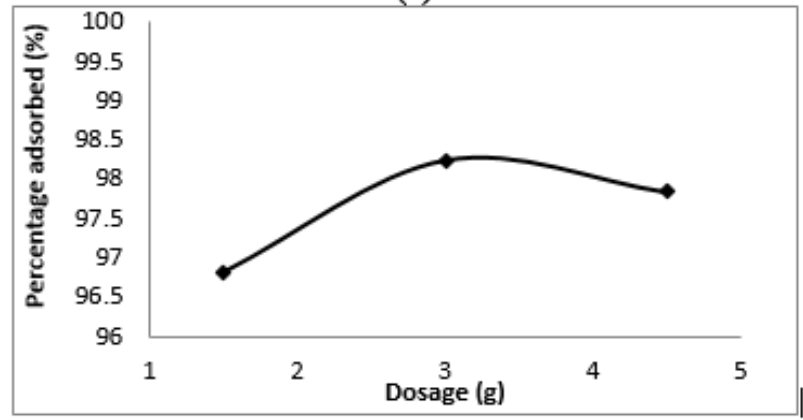

(f) 


\subsection{Influence of temperature}

The experiment was carried out at three different temperature i.e. 32,37 and $45^{\circ} \mathrm{C} .1 .5 \mathrm{~g}$ of the pan size of adsorbent was dried in an incubator for 2 hours at different temperatures to remove the moisture. The heated adsorbent was kept in $30 \mathrm{ml}$ solution of 30 ppm concentration for 90 minutes (32). The filtered solutions were given for spectrophotometry analysis and the adsorption percentage was calculated. It was found that as the temperature increases the adsorption percentage also increases but after $37 \mathrm{oC}$ temperature it decreases. This is because after a certain temperature, degradation of adsorbent starts. Therefore, it was concluded that among the tested temperature, $37{ }^{\circ} \mathrm{C}$ is the optimum temperature for adsorption (Figure 2d). Adsorption study of chromium on $\mathrm{MgO}$, showed a similar observation in the case of temperature. The maximum adsorption occurs at around $30^{\circ} \mathrm{C}$ for $\mathrm{MgO}$ which was given by Mahmood et al., 2010 (31), and the Pinus palsturis seeds take $37^{\circ} \mathrm{C}$ for maximum adsorption. The maximum adsorption of $\mathrm{Cr}$ on almond is at $45^{\circ} \mathrm{C}$ and apricot is $50^{\circ} \mathrm{C}$ which is given by Khazaei et al., 2011 (27), compared to the Pinus palsturis seeds adsorption occurs at higher temperature. This is because the Pinus palsturis seeds get decayed at high temperature.

\subsection{Influence of $\mathrm{pH}$}

To optimize the $\mathrm{pH}$ the experiment was carried out with the different $\mathrm{pH}$ values, i.e. 2, 4, 6, 8 and 10 . The $\mathrm{pH} 2,4$, and 6 are maintained by adding few drops of $0.1 \mathrm{~N} \mathrm{HCl}$ and $\mathrm{pH}$ of 8 and 10 are maintained by adding few drops of $1 \mathrm{M} \mathrm{NaOH}$. $1.5 \mathrm{~g}$ of pan size of adsorbent was heated at $37^{\circ} \mathrm{C}$ in the incubator for 2 hours. The heated adsorbent was kept in $30 \mathrm{ml}$ solution of $30 \mathrm{ppm}$ concentration for $90 \mathrm{~min}$. The filtered solutions were given for spectrophotometry analysis and adsorption percentage was calculated. It was found that as the $\mathrm{pH}$ increases adsorption percentage also increases but after a certain $\mathrm{pH}$ it decreases. It was determined from experimental data and it is shown on the graph the influence of $\mathrm{pH}$ on adsorption (Figure -2e).

\subsection{Influence of dosage}

The experiment was carried out for different dosage of the pan size adsorbent, i.e. 1.5, 3 and 4.5g. Different weights of the adsorbent were kept in the incubator at $37{ }^{\circ} \mathrm{C}$ for 2 hours. The heated adsorbent was kept in $30 \mathrm{ml}$ solution of $30 \mathrm{ppm}$ concentration with $6.5 \mathrm{pH}$ for $90 \mathrm{~min}$. The filtered solution were given for spectrophotometry analysis and the adsorption percentage was calculated. It was found that as the weight increases the adsorption percentage also increases but after a certain dosage it decreases (32). This is because adsorptive force between the adsorbent and chromium gets week at higher dosage. So it was concluded that $3 \mathrm{~g}$ of adsorbent is the optimum dosage for adsorption (Figure 2f).

The study of Boehmite nano powder on Chromium uses $2.5 \mathrm{~g}$ of the powder for maximum adsorption i.e. $60 \%$, given by Sharawy et al., 2013 (33), whereas in this study the Pinus palsturis seeds uses $3 \mathrm{~g}$ and the adsorption percentage is $98.25 \%$ in absorbing chromium. The maximum adsorption of chromium on almond and apricot is at $6 \mathrm{~g}$, which showed by Khazaei et al.,
2011 (27), compared to the Pinus palsturis seeds adsorption occurs at better dosage (Table 1).

\subsection{Adsorption Isotherms}

- Langmuir isotherm (Model 1) (Figure -3a)

$\frac{C_{0}}{M}=\frac{a b C_{e}}{1+a C_{e}}$

$\frac{C_{0}}{M}=\frac{57.4136 C_{e}}{1-3.44 C_{e}}$

$a=-3.44 b=-16.69$

- $\quad$ Freundlich Isotherm (Model 2) (Figure - 3b)

$\frac{x}{m}=K C^{1 / n}$

$\frac{x}{m}=46.5 C^{-0.66280}$

$K=46.5$

$\mathrm{n}=-1.508$

- $\quad$ BET Isotherm (Model 3) (Figure -3c)

$$
\begin{aligned}
& q_{e}=\frac{K_{B} \times C_{e} \times Q_{o}}{\left(C_{s}-C_{e}\right)\left\{1+\left(K_{B}-1\right)\left({ }^{C_{e}} / C_{S}\right)\right\}} \\
& q_{e}=\frac{1.99 \times 10^{6} C_{e}}{\left(132300-C_{e}\right)\left\{1+\left(3.646 * 10^{11}-1\right)\left({ }^{C_{e}} / 132300\right)\right\}}
\end{aligned}
$$

$\mathrm{Cs}=132300$

$\mathrm{K}_{\mathrm{B}}=3.646^{*} 10^{11}$

$\mathrm{Q}_{0}=5.485^{*} 10^{-6}$

\section{- $\quad$ Temkin Isotherm (Model 4) (Figure -3d)}

$$
\begin{aligned}
& q_{e}=\frac{R T}{b_{T}} \times \ln \left(K_{T} C_{e}\right) \\
& q_{e}=72.8393 \times \ln \left(0.4979 C_{e}\right) \\
& \mathrm{B}_{\mathrm{T}}=72.8393 \\
& \mathrm{~K}_{\mathrm{T}}=0.4979
\end{aligned}
$$

Table: 1 Adsorption Isotherms with $\mathrm{R}^{2}$ values

\begin{tabular}{|l|l|}
\hline Isotherms & $\mathrm{R}^{2}$ value \\
\hline Langmuir Isotherm & 0.9857 \\
\hline Freundlich Isotherm & 0.9961 \\
\hline BET Isotherm & 0.9172 \\
\hline Temkin Isotherm & 0.9316 \\
\hline
\end{tabular}

Table 1 shows that the Freundlich isotherm is the most suitable isotherm for the experiment, since the $\mathrm{R}^{2}$ value of the Freundlich isotherm is 0.9961 which is closer to linearity. 

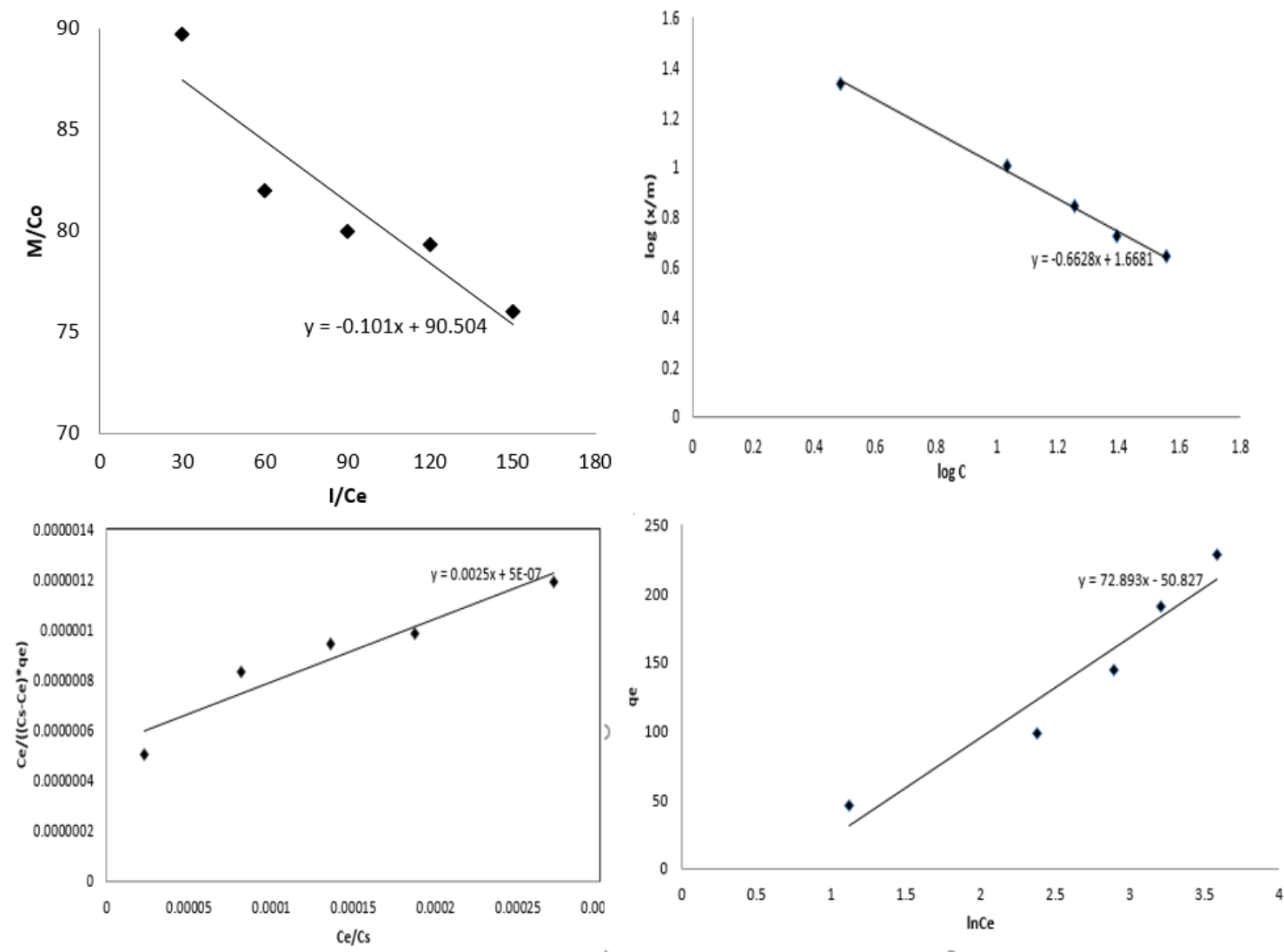

Fig. 3: (a) Langmuir Isotherm; (b) Freundlich Isotherm; (c) BET Isotherm; and (d) Temkin Isotherm

3.7 Adsorption Kinetics

- $\quad$ Pseudo first order kinetics (Figure -4a)

$\frac{d q_{t}}{d t}=K_{1}\left(q_{e}-q_{t}\right)$

$\frac{d q_{t}}{d t}=0.0619\left(118.713-q_{t}\right)$

$\mathrm{K}_{1}=0.0619 \mathrm{~min}^{-1} \quad \mathrm{q}_{\mathrm{e}}=118.73 \mathrm{mg} / \mathrm{g}$

- $\quad$ Pseudo second order kinetics (Figure -4b)

$\frac{d q_{t}}{d t}=K_{2}\left(q_{e}-q_{t}\right)^{2}$

$\frac{d q_{t}}{d t}=0.01915\left(79.36-q_{t}\right)^{2}$

$\mathrm{K}_{2}=0.01915 \mathrm{~g} \mathrm{mg}^{-1} \mathrm{~min}^{-1} \quad \mathrm{q}_{\mathrm{e}}=79.36 \mathrm{mg} / \mathrm{g}$

Table 2 shows that the Pseudo second order is the most suitable kinetics for the experiment, since the $\mathrm{R}^{2}$ value of the Pseudo second order is 0.9961 which is closer to linearity.

Table 2: Adsorptions Kinetics with $\mathrm{R}^{2}$ value

\begin{tabular}{|l|l|}
\hline Kinetics & $\mathrm{R}^{2}$ \\
\hline Pseudo first order & 0.8616 \\
\hline Pseudo second order & 0.9534 \\
\hline
\end{tabular}
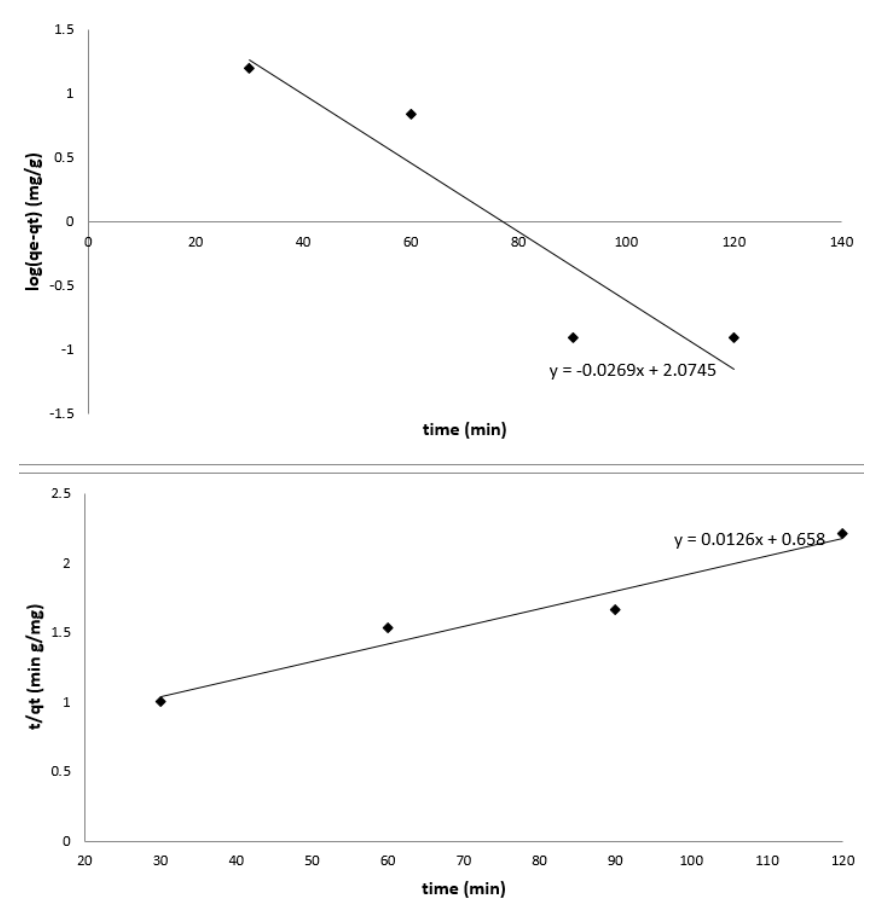

Fig. 4: (a) Pseudo first order and (b) Pseudo second order 
The analysis of the adsorbent under the influence of different parameters was concluded as the adsorption isotherms and adsorption kinetics were studied on these parameters. Instrumental analysis was done for the adsorbent to study its characteristics. The studied showed that the adsorption takes place more at lower concentration, so the further studies were done on $30 \mathrm{ppm}$ concentration. Using this concentration value, the size of the adsorbent particle was found. The fine particles have more adsorption, since the surface area increases as the size decreases. So this concluded that pan size is having more adsorption capacity. According to these concentration and size, a study was done on the contact time. It was found that after $90 \mathrm{~min}$ there was no adsorption occurring. So this is the optimum time for the adsorption process. By the above characteristics, a study was done based on temperature. The maximum adsorption was determined at $37^{\circ} \mathrm{C}$.

A pH of 6.5 was found to be the optimum when a study was conducted on different $\mathrm{pH}$. The adsorbent dosage of $3 \mathrm{~g}$ per $30 \mathrm{ml}$ was found to be the optimum concentration for adsorption. The different isotherms were done, and the regression parameter showed that Freundlich isotherm has the best fit among tested equations used for adsorption models $(34,35)$. Furthermore, the studies showed that this adsorption follows the pseudo second order kinetics (Fig 3b).

\section{Conclusion}

The adsorbent was identified as a good candidate for the removal of chromium. Different parameters such as size, temperature, contact time, concentration, $\mathrm{pH}$ and dosage were evaluated and the effective adsorption of the compounds. The adsorption was maximum at pan size, $37^{\circ} \mathrm{C}$ temperature, 30 mins - contact time, $30 \mathrm{ppm}$ - concentration, 6 - pH and $3 \mathrm{~g}$ - dosage The adsorption isotherms showed that the Freundlich Isotherm is a better adsorption model and the characteristic parameters were determined. The results of the kinetic models showed that the pseudo second order kinetics was established to be related with the experimental data. The biosorption process was endothermic and non-spontaneous. Results suggest that Pinus palustris seeds is an effective low-cost biosorbent with high biosorption capacity to remove Chromium from aqueous solutions.

\section{Acknowledgment}

Facilities provided by Sathyabama Institute of Science and Technology to carry out the study are gratefully acknowledged.

\section{Competing interests}

The authors declare that there is no conflict of interest that would prejudice the impartiality of this scientific work.

\section{Authors' contribution}

All authors of this study have a complete contribution for data collection, data analyses and manuscript writing

\section{References}

1. Tamirat Dula, Khalid Siraj, and Shimeles Addisu Kitte., 2014, Adsorption of Hexavalent Chromium from Aqueous Solution Using Chemically Activated Carbon Prepared from Locally Available Waste of Bamboo (Oxytenanthera abyssinica). ISRN Environmental Chemistry. Volume 2014, Article ID 438245, 9 pages.
2. Boschi C, Maldonado H, Ly M, Guibal E. Cd (II) biosorption using Lessonia kelps. Journal of colloid and interface science. 2011 May 15: 357(2):487-96.

3. Robak, K. and Balcerek, M., 2018. Review of second generation bioethanol production from residual biomass. Food technology and biotechnology, 56(2):174-187.

4. Ho, Y.S., McKay. G., 1999 Pseudo-second order model for sorption processes. Process Biochemistry. 34(5). 451-465.

5. Hu Yun, Wu, M.H., 2005, Removal of chromium (VI) from dilute aqueous solution by Maghemite nanoparticle. J. Water. Pollut Control. Federation. 47(8).389-393.

6. Baral SS, Das SN, Rath P. Hexavalent chromium removal from aqueous solution by adsorption on treated sawdust. Biochemical Engineering Journal. 2006 Oct 1;31(3):216-22.

7. Sas-Nowosielska A, Kucharski R, Małkowski E, Pogrzeba M, Kuperberg JM, Kryński KJ. Phytoextraction crop disposal—an unsolved problem. Environmental pollution. 2004 Feb 1;128(3):3739.

8. Rathore SS, Tiwary RK, Birendra K, Padma P. Microbial removal of Hexavalent chromium from chromite waste dump. Malaya Journal of Biosciences (MJB). 2014, 20;1(2):109-16.

9. Swami, D., Buddhi, D., 2006, Removal of contaminants from industrial wastewater through various non-conventional technologies. a review, International Journal of Environment and Pollution. 27 (4).324-346.

10. Ngah WW, Hanafiah MM. Removal of heavy metal ions from wastewater by chemically modified plant wastes as adsorbents: a review. Bioresource technology. 2008, 1;99(10):3935-48.

11. Verma, A., Chakraborty, S., Basu, J.K, 2006, Adsorption study of hexavalent chromium using tamarind hull-based adsorbents. Separation and Purification Technology. 50(3):336-341.

12. Valix, M., Cheung, W.H, Zhang, W., 2006, Role of heteroatoms in activated carbon for removal of hexavalent chromium from wastewaters. Journal of Hazardous Materials. 135 (1-3). 395-405.

13. Matlock MM, Howerton BS, Atwood DA. Chemical precipitation of heavy metals from acid mine drainage. Water research. 2002 1;36(19):4757-64.

14. Lee IH, Kuan YC, Chern JM. Equilibrium and kinetics of heavy metal ion exchange. Journal of the Chinese Institute of Chemical Engineers. 2007, 1;38(1):71-84.

15. Stafiej A, Pyrzynska K. Adsorption of heavy metal ions with carbon nanotubes. Separation and purification technology. 2007, 1;58(1):4952.

16. Bakalár, T., Búgel, M. and Gajdošová, L., 2009. Heavy metal removal using reverse osmosis. Acta Montanistica Slovaca, 14(3), 250-254.

17. Singarea, P.U, Dhabarde, S.S., 2014, Toxic metals pollution due to industrial effluents released along Dombivali Industrial Belt of Mumbai. European Journal of Environmental and Safety Sciences 2(1).5-11.

18. Hajeetha T.K. Vijayalakshmi, T, Gomathi, Sudha, P.N., 2013 , Removal of $\mathrm{Cu}(\mathrm{II})$ and $\mathrm{Ni}(\mathrm{II})$ using cellulose extracted from sisal fiber and cellulose-g-acrylic acid copolymer. International Journal of Biological Macromolecules, 62.59-65.

19. Song, Z., Williams, C.J, Edyvan, R.G.L., 2004, Treatment of tannery wastewater by chemical coagulation. Desalination. 164(3).249-259.

20. Shajahan Siraj, Md. Monarul Islam, Prokash Chandra Das, Shah Md. Masum, Ismet Ara Jahan, Md. Aminul Ahsan and Md. Shajahan., 2012., Removal of Chromium from Tannery effluent using ChitosanCharcoal Composite. Journal of Bangladesh Chemical Society. 25(1).53-61.

21. Kumiawan, T.G., Jumasiah, A., Azni. I., Katayon, S., Choong, S.Y.T., 2005 Rice husk as a potentially low-cost biosorbent for heavy metal and dye removal. An overview. Desalination, 175 (3)305-316 
22. Ho, Y.S., McKay, G, 1998, A comparison of chemisorption kinetic models applied to pollutant removal on various sorbents. Process Saf. Environ. 67(4).332-340.

23. Wongjunda J and Saueprasearsit P., 2010, Biosorption of Chromium (VI) using rice husk ash and modified rice husk ash. Environmental Research Journal. 4(3).244-250.

24. El Harti M, H. Hannache, E. Khouya, N. Hanafi, M. El Bouchti, A. Zarrouk, S. Fakhi, L. Afrin, A. Saoiabi and Hammouti. B., 2013, Hexavalent chromium removal from aqueous solution by adsorbent prepared from Moroccan oil shale of Timahdit. Der Pharma Lettre. 5(2). 338-346).

25. Aravind Kumar. J, Joshua Amarnath, D, Narendrakumar, G., Vijai Anand, K., 2018., Optimization of process parameters for naphthalene removal onto nano iron oxide/carbon composite by response surface methodology, isotherm and kinetic studies, Nanotechnology for Environmental Engineering. 3:17. https://doi.org/10.1007/s41204-018-0046-y

26. Singh V, Kumari P, Pandey S, Narayan T., 2009, Removal of chromium (VI) using poly(methylacrylate) functionalized guar gum. Bioresource Technology. 100(6). 1977-1982.

27. Alok Mittal, Lisha Kurup, Jyoti Mittal., 2007, Freundlich and Langmuir adsorption isotherms and kinetics for the removal of Tartrazine from aqueous solutions using hen feathers. Journal of Hazardous Materials. 146 (1-2).243-248.

28. Khazaei, I., Aliabadi, M. and Hamed, M.H., 2011. Use of agricultural waste for removal of $\mathrm{Cr}$ (VI) from aqueous solution. Iranian Journal of Chemical Engineering. 8(4).11-23.

29. Singh, I.B, Singh, D, R., 2002, Cr(VI) removal in acidic aqueous solution using iron-bearing industrial solid wastes and their stabilisation with cement. Environmental Technology. 23 (1).85-95.

30. El Qada, E,N., Allen, S.J., Walker, G.N., 2001, Adsorption of Methylene Blue onto activated carbon produced from steam activated Bituminous coal. A study of equilibrium adsorption isotherm. Chemical Engineering Journal. 124 (1-3).103-110.

31. Hamadi K.N.K., Chen, D,. Farid, M,M., Lu, M.G.Q., 2001, Adsorption kinetics for removal of $\mathrm{Cr}(\mathrm{VI})$ from aqueous solution by adsorbents derived from used tyres and sawdust. Chem. Eng. J. 84(2).95-105

32. Mahmood M. Barbootia, Mumtaz A. Zabloukb, Usama A. Alzubaidi., 2010, Recovery of Chromium from Waste Taning Liquors by Magnesium Oxide. International Journal of Industrial Chemistry.1(1).29-38.

33. Ying Zhang, Ru Zheng, Jiaying Zhao, Fang Ma, Yingchao Zhang, and Qingjuan Meng., 2014, Characterization of -Treated Rice Husk Adsorbent and Adsorption of Copper(II) from Aqueous Solution. BioMed Research International, Volume 2014, Article ID 496878, 8 pages

34. Sharawy., H, Ossman., M.E, and Mansour MS., 2013, Kinetics modeling and Adsorption isotherm studies for $\mathrm{Cr}$ (III) removal using Boehmite Nano-powder. International Journal of Chemical and Biochemical Sciences.3.9-18.

35. Sirianuntapiboon, S, Hongsrisuwan, T., 2007, Removal of $\mathrm{Zn}^{2+}$ and $\mathrm{Cu}^{2+}$ by a sequencing batch reactor (SBR) system. Bioresource Technology. 98(4):808-818. 